\title{
Energy Saving Design of Residential Buildings Based on Regional Technology of Climate
}

\author{
Chen Shuang \\ Department of Construction and Environmental Engineering \\ Shougang Institute of Technology \\ Beijing, China \\ e-mail: bjchensh@126.com
}

\begin{abstract}
Climate is an important factor that affects architectural design. In different regional conditions, it should have different structure and space distribution, that is, the regional technology of adaptation to climate. According to the climate characteristics of the middle and lower reaches of the Yangtze River area, this paper explores the residential building energy saving design from the building layout, architectural shading, air interlayer insulation, interior space and enclosure structure. The target is to reduce the energy consumption of buildings, create the micro climate, and basedon the regional technology to create the residential buildings adapting the climate of these areas.
\end{abstract}

Keywords-residential building; structure design; regional technology ; energy saving; climate

\section{INTRODUCTION}

The world's construction in the last century is equal to the sum of all human construction before, of course, this is from the development of society, the progress of science and technology is the embodiment of the degree of human civilization [1]. However, the limited energy has gradually exhausted, the use of natural resources destructive, the natural environment is deteriorating, the city's construction and construction development continues to face various problems [2]. We must look at our architectural design and fundamentally reduce building energy consumption. In addition, we must also adapt to the development of society, meet the needs of consumers, improve indoor comfort, and reduce air-conditioning equipment [3]. Through the introduction and research of the bio-climate local theory and some foreign new climate architecture, this paper is to explore the design principle for the construction of the Yangtze River downstream.

\section{CLIMATIC CHARACTERISTICS OF THE MIDDLE AND LOWER REACHES OF THE YANGTZE RIVER}

In the middle and lower reaches of the Yangtze River in geographic latitude roughly in the latitude of 30 degrees to 32 degrees, belong to the climate transition area, this area of the climate characteristics of summer high temperatures, continuous time up to 3-4 months, solar radiation intensity; winter is cold, for as long as 2 to 3 months, relative humidity is bigger, the seasonal wind strong [4]. Residential buildings in the area of the thermal insulation is not a reference theoretical basis, residential indoor thermal environment quality is generally poor, the winter indoor cold damp, the coldest month average indoor temperature only $4 \sim 6$ degrees; sweltering summer, indoor temperature in the hottest month up 32 degrees Celsius, especially in the top and Western room is very hot and uncomfortable [5]. Such a large number of air conditioning equipment into residential areas, due to the lack of an overall deployment, no better building thermal starting from, improving thermal environment is very limited, low efficiency of energy use, resulting in pollution of the atmospheric environment [6]. Therefore, the improvement of the indoor environment of the area has been urgent.

Under normal circumstances, the same volume, the same material, the same quality of the objects, and under the same environmental conditions, the absorbed solar radiation is equal to the heat, the fundamental difference only lies in the distribution of heat in the body.

In fact, the building insulation is the best possible radiation heat barrier outside the building, so that indoor comfortable environment, this will have to analyze the environment of the building. Construction is different from the general form, it has been into a normal form for the vitality of the space form, lighting and ventilation, which will inevitably need to have windows and doors, and solar thermal radiation will be through the doors and windows spread indoor and how to not only ensure indoor ventilation and lighting, and, to the extent possible, effectively prevent heat radiation. This requires in the design must know the area a year four seasons sun operation rules, analysis of bio climatic features of the region, the appropriate building shape, and the orientation of the building and take effective measures of building sun shading.

\section{BIO CLIMATE AND LOCAL THEORY}

Climate and geography are closely linked to the two concepts, from the last century in the twenty or thirty's to the construction and climate, architecture and regional relations [7]. Along with the progress of science and technology, the research has deepened, and the building energy efficiency has achieved some results.

In 1963, design with climate by V Ogoja: "study" bioclimatic architecture of regionalism, summarizes the various achievements of the previous 60 years of architectural design and climate, geographical relations research, put forward design theory of "bioclimatic regionalism", will satisfy the human body biological comfort (cold, heat, dry, wet etc.) as the starting point of design, focusing on the study of the relationship between 
climate, geographical and human biological sense, that the architectural design should follow the climate, biological technology, and construction process, respectively: a variety of weather conditions the research design section; influence of climate conditions on biological evaluation of each human comfort; taking to solve the contradiction between the climate and human comfort technology; combine the specific location, importance to distinguish between the various conditions, relevant technical measures taken for architectural design, design for optimization [8].

The theory of the bio - climate - Local - climate has greatly influenced the architectural design, such as the 70 time Germany adapted to the climate - saving building. India Celaya proposed the design method of form follows climate theory. From the point of view of bioclimatology of combination of geographical and climate conditions for the designers express an important means of localism and cultural characteristics, but also to meet the needs of the current social development.

\section{REGIONAL TECHNOLOGY OF RESIDENTIAL ARCHITECTURAL DESIGN IN THE MIDDLE AND LOWER REACHES OF THE YANGTZE RIVER}

In order to adapt to the climatic characteristics of the middle and lower reaches of the Yangtze River, a series of adaptive spatial patterns must be produced [9].

\section{A. Heat insulation performance of building envelope}

In the case of natural ventilation, the indoor air temperature is lower than the outdoor air temperature, and the effective method is to strengthen the external wall and window of the insulation performance. According to the insulation mechanism of the building, the solar radiation projected to the outer surface of the building was immediately reflected off, and partly absorbed. The heat absorbed outside the building is transmitted to the interior part of the building, and the other is distributed to the outdoor by the long wave radiation and air convection.

The solar radiation that is projected onto the exterior of the building is eventually distributed indoors and outdoors. Obviously, the more heat we send out, the less heat we transmit to [10]. Therefore, the reflection of the exterior of the building can reduce the heat from the house to the house. Therefore, in the middle and lower reaches of the Yangtze River, the high temperature time of the Yangtze River is usually used white or light colored finishes achieving the effect of external wall reflection heat insulation. You can also see from the figure, and ultimately to the transfer the heat to the indoor less should also reduce the heat transfer coefficient of building envelope structure, namely in the external retaining structure is provided with the heat insulating layer, isolation outside the heat to the indoor transmission, thus building exterior absorption heat will gather in large numbers on the outer surface, to promote the construction of the outer surface temperature rise, further improve the temperature difference between the outer surface of the building and the environment, conducive to the outdoor heat release. This heat insulation is also known as heat insulation [11]. The results of the reflective heat insulation and the temperature rise and heat insulation are the heat transfer of the solar radiation which is projected onto the exterior of the building to the exterior environment of the building.

The problem of the heat insulation performance of the window has always been the most important factor in the design of the external retaining structure. For the Yangtze River downstream areas is to solve the problem of the window heat insulation. In the summer to meet natural lighting at the same time, to the extent possible, the sunlight is stranded in the outdoors, at present the most commonly used method is the double glass windows, use insulating, heat insulation and reflective glass and other, but air layer is generally only about $20 \mathrm{~mm}$, and can not effectively reached the purpose of heat insulation of, to achieve the $40 \mathrm{~mm}$ only certain effect, which makes to air inter layer pressure becomes smaller, the glass must have greater strength, this certainly will increase the cost. If the air layer between the reflective materials, it will achieve better results.

\section{B. Building layout}

In the middle and lower reaches of the Yangtze River, it relieves the heat of the summer temperature. The overall layout of the building should be closely around the issue. In the construction of the layout should have larger windows stretch open, open, and conducive to natural ventilation? Adopt the deep porch and the sun shade to help air and cool down. An effective way is in the indoor set "wind tunnel" to organize drafts, "duct" must be wide enough to ensure air circulation, at both ends of the air duct can also set the tent or porch to guide wind, sun and rain shielding effect, as shown in Fig.1.

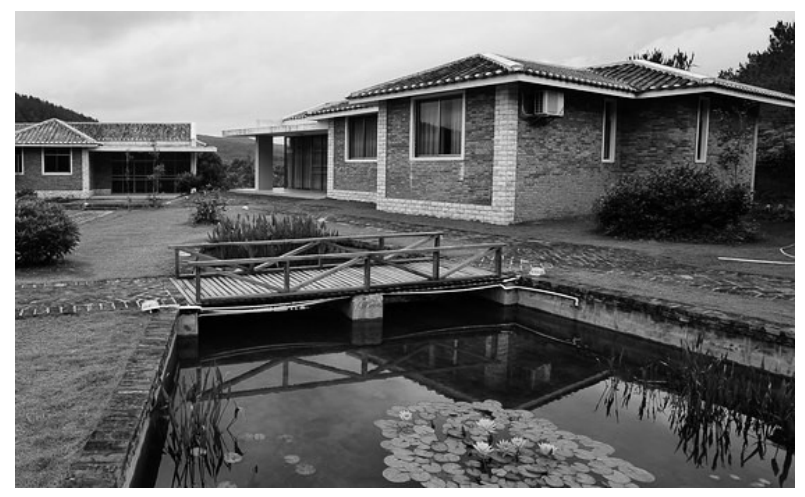

Figure 1. Residential building layout

\section{Internal space organization and division}

Buildings in the area have a significant feature; open the plane form, similar to the modern architecture in the flow space, but function more comprehensive. Therefore, in the region within the ideal architectural layout: a long line of plane and profile with the top of the hill, all rooms have direct lighting and ventilation; around the building has balcony, louver plate or veranda. Many of the layouts of the form of traditional architecture, but in a large number of multi-storey and high-rise residential units, due to the requirements of the density and the volume rate, modern residential tend to have greater depth. Therefore, it is necessary to ensure that a set of housing in different range of housing between a smooth airflow, forming a draught, as shown in Fig.2. 
With the concept of social development and people's living level increasing, people on residential buildings each have become increasingly demanding, for living space environment more attention, residential design in the "Hall of small lie" for adaptation of modern residential concept changes came into being, it reflects the development trend of residential building is a symbol of the progress of residential design.

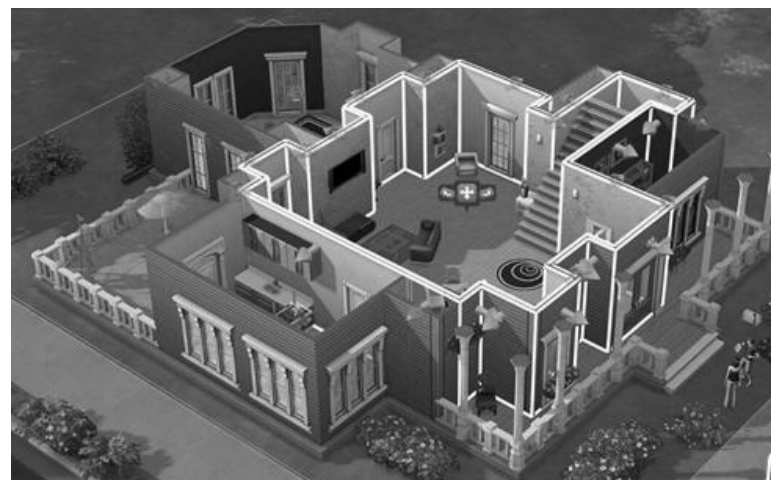

Figure 2. Internal space organization and division

The problem of space composition, function partition and area allocation in the small room of the architectural design. Should pay attention to the area distribution of the dialectical relationship between the office of lying, emphasizing the issues related to the architecture design methods in the "Hall of small lie" design, in order to ensure the "Hall of small lie" residential have good space environment and effects, and a strong sense of it.

The above building in the face of natural geographical and climatic conditions create, after years of temper and the formation of regional technology is a simple, generalized ecological design. The principle of "suit to local conditions" and the idea of creating environment microclimate by means of ecological design are the important means of design.

\section{THE APPLICATION OF STRUCTURAL DESIGN IN THE DESIGN OF RESIDENTIAL BUILDINGS}

According to the different regional climate features, a set of corresponding architectural design is constructed, which is the goal of the construction field. The basic idea is that it is not dependent on energy consuming equipment, but measures are taken in architectural form, space layout and structure to improve building environment and realize microclimate construction.

The works of India architect Chorea have a favorable comment on the design idea. In order to solve the hot and dry climate and building ventilation, Kelley proposed "open space" and "tube housing". The former reflects the shadow of outdoor and semi outdoor space more suitable for dry heat area public belief; the latter the chimney ventilation principle is applied to the design section, in the bottom of high density residential groups can create shadow miniaturization of the outdoor space, and effectively solve the indoor air circulation problems, and a direct result of the directly reflect the climatic characteristics of the image of the building.

According to the different height angles of winter and summer sun, the effective use of sunlight and shade measures is formulated. Setting sun and central greenhouse in residential buildings, the winter sun and central greenhouse can fully absorb solar radiation heat and provide heat for residential, at this time will pull the blinds, roof ventilation air inlet and outlet closed.

Summer sun and central greenhouse shutter is open can block the sun, double roof of the air inlet and the outlet louver in nighttime and daytime moments is open, to take away the air layer is heated in air to avoid the indoor temperature is too high.

Summer sunshine during the day at the bottom and at the top of the window, and central greenhouse at the top of the window is open, use ventilation to take the heat, night, open ventilation tower at the top of the shutter, the hot pressing effect to promote residential ventilation, to cool the building components and improve the daytime indoor thermal environment. In addition, the underground duct system cools the outdoor air and into the courtyard in the center.

In the middle and lower reaches of the Yangtze River, we can find many similar architectural forms: dry column building, platform, ventilation roof, etc. as shown in Fig.3. This is the labor people according to the local climate characteristics, created by the architectural form, is a building culture embodied. In the architectural design should find a succession of cultural ideas on climate and environment design, because the climate not only affect the construction of a natural environment, but also closely related to the culture, should implement the idea of "form follows weather". As far as possible, the culture of the region is a deeper level of the pursuit and thinking.

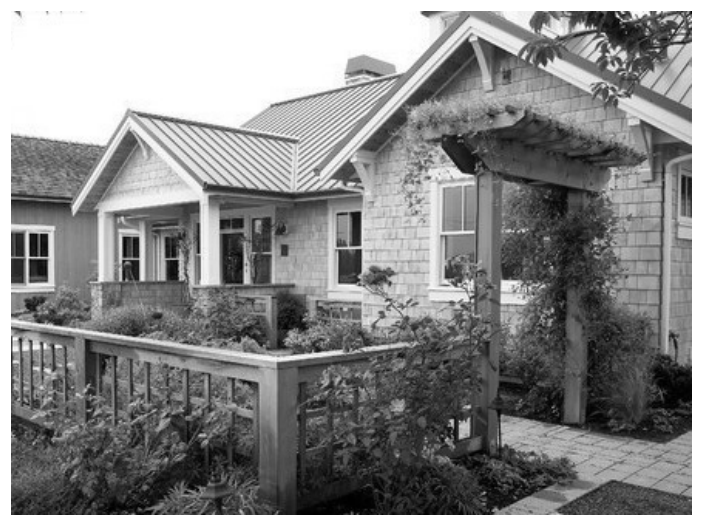

Figure 3. Southern residential building form

\section{CONCLUSION}

The discussion of the habitat environment has always been the concern of the construction industry. Whether in building energy saving, reducing building energy consumption, or improving the living comfort, creating new residential buildings, have achieved great results. But in the face of this huge building, the building energy consumption is obvious, and the energy consumption will be determined by the energy.

In different location, the energy saving measures adopted are not the same, the study of the regional technology is also the primary key problem. The suggestions mentioned in this paper are a small part, we want to realize the real energy saving in the building, but 
also the construction industry colleagues unremitting efforts.

\section{ACKNOWLEDGEMENTS}

This work was financially supported by the Beijing higher Education Young Elite Teacher Project (No. YETP1829).

\section{REFERENCES}

[1] Fu, C. Q. “Analysis of green energy saving technology in intelligent building”. Intelligent Building, vol.18, Jun. 2010, pp.1720.

[2] F. Li. "Important role of green building to the construction of low carbon city", Chinese Construction, Vol. 18, Apr. 2011, pp.70-72.

[3] X. L. Fan. "Sustainable development of building environment". Technology and Economy Market, vol.12, Oct. 2008, pp.40-42.

[4] Y. Sun, Y. Bai, X. Liang. Architectural Aesthetics and Energy Efficiency Design Business, Industrial and Administrative Office, Bejing: China Building Industry Press, 2009.
[5] L. X. Cao. "The development trend of green building design", China New Technology and New Products, Vol. 11, Nov. 2010, pp.172-173.

[6] F. Li. "Important role of green building to the construction of low carbon city”, Chinese Construction, Vol. 18, Jul. 2011, pp.70-71.

[7] Q. He. City Planning Principle. Bejing: China Architecture Industry Press, China, 2011.

[8] J. H. Han, J. G. Li, Q. Wang. "Indoor pollution sources detection technology and equipment development”, Construction Technology, Vol. 18, Sep. 2011, p.39-41

[9] D. S. Liu. “Control of Indoor Pollutants”, Northern Environment, Vol. 10, Orc. 2012, pp. 193-195

[10] L. X. Cao. “The development trend of green building design”, China New Technology and New Products, Vol.30, Dec, 2013, pp.172-174

[11] F. Li. "Important role of green building to the construction of low carbon city”, Chinese Construction, Vol. 25, Sep. 2014, p.70-73. 